\title{
Time Management Tendency of Undergraduates in Medical Colleges and Its Influencing Factors
}

\author{
Hou Yongmei * \\ Department of Psychology, School of Humanities and \\ Management \\ Guangdong Medical University \\ Dongguan, Guangdong 523808, China \\ *Corresponding author 352314640@qq.com
}

\author{
Yuan Miner \\ Department of Psychology, School of Humanities and \\ Management \\ Guangdong Medical University \\ Dongguan, Guangdong 523808, China
}

\begin{abstract}
To investigate the developmental characteristics and its influenced factors of time management disposition in the undergraduates of medical university. Seven hundred and seventy-two undergraduates who were selected by Stratified sampling from a medical university in Guangdong were assessed with Adolescence Time Management Disposition Inventory (ATMDI), as well as a self-edited questionnaire on the general information. (1) Time Management Disposition had significant differences in the following factors: specialization interest, family economics, the level of professional understanding, whether class leaders or not. (2) Multiple regression analys is showed that the mainly influenced factors of the total score of ATMDI were as following: family pecuniary condition, whether class leaders, professional interest, professional prospect, professional understanding, the degree of satisfaction on the teachers' professional knowledge and teaching level, the daily life in school, and recreational and sports activities. The mainly influenced factors of the time management disposition in the undergraduates in the medical university involve family, the sense of professional identity and the running manner of the school.
\end{abstract}

Keywords-Undergraduates; Time Management Disposition; Influenced Factors

\section{RESEARCH}

Time management refers to the plan and control activities of individuals in order to make good use of time resources, the purpose of which is to make the individual from the state of passive and natural use of time to active, systematic, centralized, purposeful and planned distribution and use of time, so as to carry out efficient and creative labor.

Time management is a stable personality trait, which has a profound impact on individual life. For College students, good time management can stimulate learning motivation ${ }^{[1]}$, reduce academic delay ${ }^{[2]}$, increase learning input ${ }^{[1]}$, promote autonomous learning ${ }^{[3]}$, and improve academic performance ${ }^{[4]}$. Time management can also significantly affect the physical and mental health of college students: time management tendencies are independent predictors of sleep quality ${ }^{[5]}$, which can reduce the positive predictive effect of psychological stress on anxiety ${ }^{[6]}$ and improve mental health ${ }^{[2]}$.

The influencing factors of time management include demographic variables such as gender, grade level, place of origin, whether they are only children or student cadres ${ }^{[7-8]}$, family education factors, such as the father's severe punishment, excessive protection, mother punishment severely, excessive interference protection ${ }^{[9]}$, school education factors, such as professional recognition ${ }^{[10]}$, and personality characteristics, such as the just world belief $^{[4]}$, type A personality ${ }^{[11]}$ and positive psychological capital $^{[8]}$.

Regarding the influencing factors of time management, the results of previous studies are mostly biased and fragmented, and the conclusions are inconsistent in the role of certain factors ${ }^{[7-8]}$. The reason is that most of these studies use convenient sampling methods, and the representativeness of the samples is insufficient. In the statistical analysis, one-way analysis of variance is often used, and multiple factors cannot be combined.

\section{A. Objects and Tools}

A stratified random sampling method was used to select 820 undergraduates from a medical university. The adolescent Time Management Disposition Scale and the self-designed questionnaire were used to conduct a questionnaire survey. A total of 772 valid questionnaires were collected and the effective rate of the questionnaire was $94.1 \%$. Among them, there are 420 boys and 352 girls, 175 freshmen, 156 sophomores, 154 juniors, 148 seniors and 139 seniors, 435 medical students, 141 science students, 70 engineering students, 45 liberal arts students, and 81 liberal arts and Sciences students.

\section{B. Research Tool}

1) Adolescence Time Management Disposition Inventory (ATMDI) [12]

A total of 44 projects were compiled by Huang Xiting and Zhang Zhijie. They were divided into the following three subscales: time value subscale (including two dimensions of social orientation and personal orientation), time monitoring subscale (including five dimensions of setting goals, planning, priority, time allocation and feedback) and time efficacy scale (including two dimensions of time management effectiveness and time management behavior effectiveness). Using Likert 5-point scoring, from "complete non-conformity" to "complete conformity" were assessed as 1-5 points, the higher the score, the higher the individual's time management propensity. The Cronbach'a coefficient of the aggregate scale is 0.909 , the Cronbach'a coefficient of each subscale is $0.842-0.880$, the retest reliability of the aggregate scale is 0.864 , and the retest reliability of each subscale is 0.816-0.838.

2) Self Compiled Questionnaire on Influencing Factors of Time Management

16 items are included, including gender, grade, how many children do parents have, family economic status, 
whether they have served as student cadres, professional categories, whether parents support the majors they are studying, whether they are willing about their majors, their professional interests, their confidence in the professional prospects, knowledge of professional-related work, satisfaction with teachers' knowledge reserves and teaching methods, satisfaction with school management systems, satisfaction with school daily life, satisfaction with research activities attended by students, satisfaction with school entertainment activities, etc.

\section{Data Processing}

The data was processed and analyzed using spss20.0. The main analytical methods are descriptive statistics, independent sample t test, one-way analysis of variance (ANOVA), multiple linear regression, and so on.

\section{RESULTS}

\section{A. Overall Level of Time Management}

It can be seen from TABLE I that the time management tendencies of this group of college students are at a medium level. Among them, the time value is strong, the time efficiency is second, and the time monitoring concept is the weakest.

TABLE I. MEAN AND ST ANDARD DEVIATION OF ATMDI SUBSCALES AND DIMENSIONS

\begin{tabular}{l|l|l|l|l}
\hline Subscale/dimension & Mean & SD & N (number of entries) & Mean/N \\
\hline Time value & $\mathbf{3 5 . 9 2}$ & $\mathbf{5 . 4 9 8}$ & $\mathbf{1 0}$ & 3.592 \\
\hline 1.Personal orientation & 17.81 & 2.772 & 5 & 3.562 \\
\hline 2.Social orientation & 18.12 & 3.512 & 5 & 3.624 \\
\hline Time monitoring concept & $\mathbf{7 6 . 6 9}$ & $\mathbf{1 1 . 7 4 9}$ & $\mathbf{2 4}$ & $\mathbf{3 . 1 9 5}$ \\
\hline 3.Set target & 15.14 & 2.972 & 5 & 3.028 \\
\hline 4.Plan & 14.75 & 3.403 & 5 & 2.950 \\
\hline 5.Priority & 17.66 & 2.774 & 5 & 3.532 \\
\hline 6.Feedback & 15.72 & 3.544 & 5 & 3.144 \\
\hline 7.Time management & 13.44 & 2.595 & 4 & 3.360 \\
\hline Time effectiveness & $\mathbf{3 3 . 9 8}$ & $\mathbf{5 . 2 6 3}$ & $\mathbf{1 0}$ & 3.398 \\
\hline 8.Time management effectiveness & 17.51 & 2.942 & 5 & 3.502 \\
\hline 9.Time management behavioral effectiveness & 16.47 & 3.121 & 5 & 3.294 \\
\hline Total score of the scale & $\mathbf{1 4 6 . 6 0}$ & $\mathbf{1 9 . 4 7 2}$ & $\mathbf{4 4}$ & $\mathbf{3 . 3 3 2}$ \\
\hline
\end{tabular}

\section{B. Univariate Analysis of Time Management Level}

Firstly, we assign the possible variables (alternative answers) that may affect the total score of ATMDI, as shown in TABLE II.

TABLE II. VARIABLE ASSIGNMENT

\begin{tabular}{|c|c|c|}
\hline & Item & Options and assignments \\
\hline 1 & Grade & $1=$ freshman, 2 = sophomore, 3 = junior, $4=$ senior, 5 = five grade \\
\hline 2 & Gender & 1=male, $2=$ female \\
\hline 3 & How many children do your parents have? & $1=1,2=2,3=3,4=4,5=5$ or more \\
\hline 4 & Whether you have served as a cadre & $1=$ No, $2=$ Yes \\
\hline 5 & Family's financial situation & 1 = poverty, 2 = food and clothing, 3 = well-off, 4 = wealthy \\
\hline 6 & Parents' support for the major they are reading & 1=very unsupported, $2=$ not supported, $3=$ not involved, $4=$ =omparative support, $5=$ =very support \\
\hline 7 & whether they are willing about their majors & $1=$ accept adjustment, 2 = volunteer \\
\hline 8 & Professional interest & $\begin{array}{l}\text { 1=I have never been interested, } 2=\text { be interested at first, not interested later } 3=\text { not interested at first, } \\
\text { interested later } 4=\text { always interested }\end{array}$ \\
\hline 9 & Confidence in professional prospects & 1=very pessimistic, 2=not optimistic, 3=general, 4=more optimistic, 5=very optimistic \\
\hline 10 & Awareness of the majors studied & 1=Not at all, 2=Understanding, 3=Generally understood, 4=Learn more \\
\hline 11 & Professional category. & 1=Medical, 2=Science, 3=Engineering, 4=Liberal Arts, 5=Cultural and science Cross \\
\hline 12 & $\begin{array}{l}\text { Satisfaction with teachers' knowledge reserve and } \\
\text { teaching methods }\end{array}$ & 1=very dissatisfied, $2=$ not satisfied, $3=$ unclear, 4=basic satisfied,5=very satisfied \\
\hline 13 & Satisfaction with the school management system & 1=very dissatisfied, $2=$ not satisfied, $3=$ =unclear, $4=$ basic satisfied,5=very satisfied \\
\hline 14 & Satisfaction with school daily life & 1=very dissatisfied, $2=$ not satisfied, $3=$ =unclear, $4=$ basic satisfied, $5=$ very satisfied \\
\hline 15 & Satisfaction with student research activities & 1=very dissatisfied, $2=$ not satisfied, $3=$ =unclear, $4=$ basic satisfied, $5=$ very satisfied \\
\hline 16 & $\begin{array}{l}\text { Satisfaction with the school's cultural and sports } \\
\text { activities }\end{array}$ & 1=very dissatisfied, $2=$ not satisfied, $3=$ unclear, $4=$ basic satisfied, $5=$ very satisfied \\
\hline
\end{tabular}

Then, single factor ANOVA was used to analyze all possible variables that affect the total score of ATMDI, as shown in TABLE III.

TABLE III shows that there were no significant differences in ATMDI scores among six factors: grade, sex, parental number of children, parental support for the major, willingness to study, and professional category. The remaining 10 items had a significant effect on the total score of ATMDI $(\mathrm{t} / \mathrm{F}=$ 2.646, both $\mathrm{p}<0.01$ ). 
TABLE III. SINGLE FACTOR ANALYSIS OF POSSIBLE FACTORS INFLUENCING TOT AL SCORE OF TIME MANAGEMENT ATMDI

\begin{tabular}{c|c|c|c}
\hline \multicolumn{2}{c|}{ Item } & $\boldsymbol{t} / \boldsymbol{F}$ & P value \\
\hline 1 & Class & 1.229 & .297 \\
\hline 2 & Gender & -.266 & .791 \\
\hline 3 & How many children do your parents have? & 197 & .898 \\
\hline 4 & Have you served as a class cadre? & -2.646 & .008 \\
\hline 5 & Family economic situation & -4.374 & .005 \\
\hline 6 & Parents' support for their majors & -2.362 & .070 \\
\hline 7 & whether they are willing about their majors & -1.260 & .208 \\
\hline 8 & Professional interest & -15.315 & $<.001$ \\
\hline 9 & Confidence in professional prospects & -16.362 & $<.001$ \\
\hline 10 & Knowledge of professional related work & -12.942 & $<.001$ \\
\hline 11 & Professional category & -.884 & .473 \\
\hline 12 & Teachers' knowledge reserves and teaching methods satisfaction & -8.516 & $<.001$ \\
\hline 13 & Satisfaction with school management system & -8.820 & $<.001$ \\
\hline 14 & Satisfaction with school daily life & -13.090 & $<.001$ \\
\hline 15 & Satisfaction with student research activities & -13.123 & $<.001$ \\
\hline 16 & Satisfaction with the school's cultural and sports activities & -12.318 & $<.001$ \\
\hline
\end{tabular}

\section{Multiple Linear Regression Analysis of the Main Influencing Factors of Time Management Disposition}

Taking the total score of ATMDI as dependent variable and the factors that have significant influence on the total score of ATMDI as independent variable, multiple linear regressions were carried out. The results show that Taking the total score of ATMDI as dependent variable and the factors that have significant influence on the total score of ATMDI as independent variable, multiple linear regression was carried out.
The results were shown in Table 4 within 95\% confidence interval.

From TABLE IV, we can see that 8 factors are positive for time management inclination, such as family economic status, student cadres, professional interests, confidence in professional prospects, understanding of professional related work, satisfaction with teachers' knowledge reserves and teaching methods, satisfaction with school daily life, satisfaction with school sports activities, etc.

TABLE IV. MULTIPLE LINEAR REGRESSION ANALYSIS OF THE MAIN INFLUENCING FACTORS OF ATMDI TOT AL SCORE

\begin{tabular}{|c|c|c|c|c|c|c|c|c|}
\hline & \multicolumn{2}{|c|}{$\begin{array}{l}\text { Unstandardized } \\
\text { Coefficients }\end{array}$} & \multicolumn{3}{|c|}{ Standard coefficient } & \multicolumn{3}{|c|}{ Relevance } \\
\hline & B & $\begin{array}{c}\text { Standard } \\
\text { error }\end{array}$ & $\begin{array}{c}\text { Trial } \\
\text { version }\end{array}$ & t value & $P$ value & $\begin{array}{l}\text { Zero } \\
\text { order }\end{array}$ & partial & $\begin{array}{c}\text { compon } \\
\text { ent }\end{array}$ \\
\hline (constant) & 3.300 & .174 & - & 19.013 & $<.001$ & - & 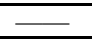 & - \\
\hline Student cadres? & .084 & .031 & .092 & 2.699 & .007 & .095 & .098 & .090 \\
\hline Family economic situation & .047 & .022 & .073 & 2.101 & .036 & .107 & .076 & .070 \\
\hline Professional interest & .036 & .017 & .084 & 2.063 & .039 & 168 & .075 & .069 \\
\hline Confidence in professional prospects & .060 & .023 & .102 & 2.621 & .009 & .225 & .095 & .088 \\
\hline Knowledge of professional related work & .059 & .027 & .082 & 2.196 & .028 & .175 & .080 & .073 \\
\hline $\begin{array}{l}\text { Knowledge of teachers and satisfaction with teaching } \\
\text { methods }\end{array}$ & .046 & .016 & .112 & 2.826 & .005 & .200 & .102 & .094 \\
\hline Satisfaction with school daily life & .045 & .017 & .110 & 2.676 & .008 & .231 & .097 & .089 \\
\hline Satisfaction with school sports activities & .047 & .019 & .111 & 2.544 & .011 & .236 & .092 & .085 \\
\hline
\end{tabular}

\section{DISCUSSIONS}

The results of this study show that college students' time management tendencies are in the middle level, in which time values are strong, time efficacy is second, and time monitoring is the weakest. Consistent with the results of previous studies [4-7], it suggests that there is still much room for improvement in the time management tendencies of college students.

This study found that eight factors were time management inclination: family and family economic status, student cadres, professional interests, confidence in professional prospects, understanding of professional related work, satisfaction with teachers' knowledge reserves and teaching methods, satisfaction with school daily life, satisfaction with school sports activities, etc.
The effect of family economic status on time management disposition essentially reflects the effect of family upbringing on individual personality (time management disposition), which is consistent with previous research results ${ }^{[13]}$. From the results of one-way ANOVA, this effect is mainly reflected in the concept of time monitoring $(\mathrm{F}=7.392, \mathrm{P}<0.001)$, that is, the better the family economic situation of College students, the stronger the concept of time monitoring. The reason is that in wealthy families, parents are mostly successful in their careers, or succeed in entrepreneurship. They have a relatively strong ability to use and manage time. They can set goals more correctly, objectively assess priorities, rationally arrange schedules, scientifically allocate time, and check results in a timely manner. In this way, work efficiency can be improved; more results or wealth can be achieved, so that the economic situation of the family can be improved ${ }^{[14]}$. Influenced by their 
parents, children also have a stronger sense of time monitoring than their peers.

Being a class cadre is helpful to improve individual's time management ability, which is consistent with Zhang Fengli' s research results ${ }^{[7]}$. This study found that the differences were mainly reflected in time values $(\mathrm{t}=2.659, \mathrm{P}=0.008)$ and time monitoring $(\mathrm{t}=2.362, \mathrm{P}=0.018)$. Compared with other college students, class cadres need to take into account the same heavy learning tasks and class management affairs, time for them means more job possibilities and learning opportunities. They also need to use their time efficiently: they must learn to plan their time scientifically and use it flexibly, especially when dealing with the relationship between the whole time and the odds and ends.

Professional interest, confidence in professional prospects, and understanding of professional related work reflect the degree of individual identification and commitment to the profession, which is consistent with the research results of Liu Guirong ${ }^{[10]}$, Du Li ${ }^{[15]}$. The results of one-way ANOVA showed that the above three factors had significant main effect on the total score and three subscales of time management disposition $(\mathrm{F}=4.882-16.263, \mathrm{P}<0.01)$. The more persistent the professional interest, the more confident the professional prospects, and the more familiar the students with the professional work, the more able they are to make time plans for their study and life. Students who have short professional interests, lack confidence in their professional prospects, and have little knowledge of relevant professional work often fail to deal with the relationship between professional study and hobbies, and lack reasonable planning for professional study.

Satisfaction with teachers' knowledge reserve and teaching methods $(\mathrm{F}=5.936-9.211, \mathrm{P}<0.001)$, school daily life $(\mathrm{F}=$ 6.075-8.820, $\mathrm{P}<0.001)$ and school sports activities $(\mathrm{F}=$ 7.378-12.318, $\mathrm{P}<0.001$ ) reflected college students' confidence in the school running level. Those who are satisfied with the above 3 aspects have higher confidence in school running level. They believe that schools can train themselves to be talented, so they can concentrate, plan their time rationally and make full use of it to study. However, college students who are not satisfied with the above three aspects often spend more time to pay attention to and blame the school running, thus reducing the planning and investment of learning.

\section{CONCLUSIONS}

Similar to other schools and other majors in China, undergraduates' time management tendencies in medical colleges and universities are in the middle level. As a stable personality trait, time management disposition of medical college undergraduates is influenced by family factors, school running level, professional identity and personal efforts. Family factors mainly include family economic status, which reflects the role of family atmosphere and family rearing patterns. The school-running level includes three factors: satisfaction with teachers' knowledge reserve and teaching methods, satisfaction with school daily life and satisfaction with school sports activities, showing college students' confidence in school-running level, and also the influence of school education and teaching methods on students.
Professional identity includes three factors: professional interest, confidence in professional prospects, and understanding of work related to the profession. They affect students' degree of study and devotion, and also affect students' timing of professional learning and extracurricular interest. Individual effort refers to the various practical activities that students take part in, such as serving as class cadres, reflecting the role of the individual in the training of students.

\section{REFERENCES}

[1] Huang Haiyan, Xu Guocheng, Fu Ying. The Relationship between College Students' Achievement Goal Orientation and Learning Input: The Mediating Role of Time Management Tendency[J]. Psychology Exploration. 2017,37(4):375-379.

[2] Qing Zaihua, Wu Caihong, Cao Jianping. The Influence of College Students' Time Management Disposition on Mental Health: The Mediating Role of Academic Procrastination[J]. Journal of Changsha University.2018,32(4):140-142.

[3] Dai Xin. Study on the Relationship between Professional Identity, Time Management Tendency and Self-directed Learning of "90s" Higher Vocational Students_-Taking the Four Schools in Anhui Province as an Example[D]. Master's thesis of Guizhou Normal University, 2016, 05 .

[4] Zhang Mei, Huang Silin, Sun Ling, et al. The Influence of Fair World Belief on College Students' Academic Achievements: An Explanation of Time Management[J]. Psychological Development and Education. 2018,34(3): 330-337.

[5] Yang Yifan, Zhang Yajie, Qi Jing, et al. The Influence of Time Management Tendency and Sleep Type on Sleep Quality of A Sophomore in A University [J]. Shanghai Preventive Medicine. 2018, 30(3): 202-207.

[6] Chen Shimin, Sun Peiyu, Wang Runhua, et al. The Regulating Effect of Time Management Tendency on the Relationship between Stress and Anxiety of College Students[J]. Chinese Journal of Clinical Psychology. 2011,19(5):423-427.

[7] Zhang Fengli.Study on the Time Management Disposition of College Students in Applied Universities[J]. Education and Teaching Forum.2018,(16):20-23.

[8] Ma Yimeng \& Li Xiang. Correlation between positive psychological capital and time management tendency of medical college students[J]. Journal of Xinxiang Medical College. 2017,34(9):809-812.

[9] Shi Guiy ing, Yan Kunlun \& Chen Wei. Regression Analysis of Parental Rearing Style and Time Management Tendency of Higher Vocational Students on Mental Health[J]. Educational Teaching Forum.2018,(32):75-78.

[10] Liu Guirong, Du He \& Zhang Xiaohan. The Influence of Professional Identity on College Students' Social Anxiety: The Mediating Role of Time Management Tendency[J]. Journal of Qilu Normal University. 2017, 32(5):22-24.

[11] Di Min, Huang Xiting, Zhang Yonghong. Study on the relationship between time management tendency and type A personality of college students[J]. Chinese Journal of Clinical Psychology.2004,12(2):154-155.

[12] Huang Xiting \& Zhang Zhijie. Preparation of the Time Management Disposition Scale for Adolescents[J]. Acta Psychologica Sinica, 2001, 33(4): 338-343.

[13] Xu Lixin. Research on the Correlation between Time Management Disposition and Parental Rearing Patterns of College Students[J]. Heilongjiang Higher Education Research.2017,(1):43-47.

[14] (US) Stephen Covey. Seven Habits of High-performance People [M] Wang Chibing et al., Beijing. China Youth Press, 2012.

[15] Du Li, Zhang Qing \& Xiao Jingjing. Relationship between Time Management Tendency and General Self-efficacy and Anxiety of Undergraduate Nursing Students[J]. Chinese Journal of Nursing.2012,47(5): 430-433. 